\title{
Antihypertensive effect of diet compared with drug treatment in obese men with mild hypertension
}

\author{
Antje/Berglund, Ove K/Andersson, Göran/Berglund, Björn/Fagerberg
}

sident

Medical Department I, Sahlgren's Hospital, 'Gothenburg University, -S 41345 Gothenburg, Sweden

Antje Berglund, MD, resident

Ove K Andersson, MD, senior lecturer

Björn Fagerberg, MD, senior lecturer

Medical Department, Malmö Allmänna Hospital, University of Lund, Malmö, Sweden

Göran Berglund, MD, professor

Correspondence and requests for reprints to: $\mathrm{Dr}$ Fagerberg.

Abstract

Objective-To determine whether dietary treatment has a similar antihypertensive effect to conventional drug treatment while being superior to drugs in improving serum lipid concentrations in obese men with mild hypertension.

Design-Six week run in period followed by randomisation to either diet or drug treatment groups for one year.

Setting-Outpatient clinic in city hospital.

Patients-61 Men aged 40-69 years, body mass index $\geq 26$, diastolic blood pressure $90-104 \mathrm{~mm} \mathrm{Hg}$ when untreated. Exclusion criteria were signs of organ damage secondary to hypertension and diseases that might have interfered with compliance or with interpretation of results.

Interventions-Dietary treatment was based on weight reduction, restriction of sodium, and decrease of excess alcohol intake (defined as $\geq 250 \mathrm{~g}$ alcohol per week). Drug treatment used a stepped care approach with atenolol as drug of first choice.

Main outcome measures-Diastolic blood pressure $<90 \mathrm{~mm} \mathbf{H g}$; absolute reductions in blood pressure and serum lipid concentrations.

Results-Mean body weight decreased $7.6 \mathrm{~kg}$ in the diet group and increased $0.9 \mathrm{~kg}$ in the drug treatment group $(p<0.0001)$, and mean sodium excretion decreased 42 and $10 \mathrm{mmol} / 24 \mathrm{~h}$ respectively $(p=0.019)$. There was no difference in reported alcohol intake. Mean systolic blood pressure decreased $4 \mathrm{~mm} \mathrm{Hg}$ in the diet group and $16 \mathrm{~mm} \mathrm{Hg}$ in the drug group $(p=0.0003)$ and diastolic blood pressure 3 and $11 \mathrm{~mm} \mathrm{Hg}$ respectively $(p=0.002)$. Diastolic blood pressure of $90 \mathrm{~mm} \mathrm{Hg}$ was attained by $29 \%$ of the diet group (nine men) and $73 \%(22)$ of those receiving drug treatment (mean difference $44 \%, 95 \%$ confidence interval 21 to $67 \%, p=0.001$ ). Dietary treatment produced decreases in mean serum concentrations of total and low density lipoprotein cholesterol as well as triglycerides and an increase in high density lipoprotein cholesterol concentration. In the drug treatment group the changes were in the opposite direction, and the groups differed significantly in all but total cholesterol.

Conclusions-Dietary treatment was inferior to conventional drug treatment in controlling mild hypertension but superior in lowering serum concentrations of lipids. //

\section{Introduction}

Managing mild hypertension is an important but complicated issue. On one hand, most patients with high blood pressure are mildly hypertensive. On the other hand, treatment to prevent complications becomes less effective the milder the hypertension. This theurapeutic dilemma of benefit versus risk with drug treatment has been met by international and national guidelines that recommend non-pharmacological measures as the first line treatment in uncomplicated cases.

The alternative treatment modalities concern various dietary factors. Obesity is common among people with hypertension, and weight reduction is generally agreed to lower blood pressure. ${ }^{1-4}$ Restriction of sodium intake and of excess alcohol consumption have also been advocated. ${ }^{12+}$ The main shortcoming of these recommendations is the lack of knowledge of whether such dietary programmes have the same favourable effect on morbidity associated with hypertension as do antihypertensive drugs. Long term studies comparing non-pharmacological programmes with conventional drug treatment are therefore necessary, and they must consider not only feasibility and antihypertensive measures but also effects on metabolic factors and structural changes in the cardiovascular system due to hypertension.

In the present study we investigated and treated obese men with mild hypertension for one year. The objectives were to create an effective dietary programme; to evaluate its feasibility in clinical practice; and to analyse whether such treatment has a similar antihypertensive effect as conventional drugs while being superior to drug treatment in improving other risk factors such as serum lipid concentrations.

The intervention was based on principles known to lower blood pressure: weight reduction, mainly by reducing intake of saturated $\mathrm{fat}^{1-4}$; restriction of sodium intake ${ }^{124}$; a decreased excess consumption of alcohol $^{124}$; and increased intake of polyunsaturated fat ${ }^{5}$ and potassium. ${ }^{4}$

\section{Methods}

The participants were men aged 40-69 years with obesity (defined as a body mass index $\geq 26^{6}$ ) and primary mild hypertension. Eligibility criteria were diastolic blood pressure of $90-104 \mathrm{~mm} \mathrm{Hg}$ for untreated patients and $\leq 95 \mathrm{~mm} \mathrm{Hg}$ for patients being treated with antihypertensive drugs. The lower limit for treated patients was chosen to avoid participants having severe hypertension after drug withdrawal. Exclusion criteria were angina pectoris, previous myocardial infarction, heart failure, evidence of cerebrovascular disease, peripheral artery disease, diabetes mellitus according to the World Health Organisation's criteria, ${ }^{7}$ renal damage defined as serum creatinine concentration $>125 \mu \mathrm{mol} / \mathrm{l}$ or clearly positive dipslide test result, chronic severe disease, and obvious alcoholism.

After an initial evaluation to determine eligibility the patients went through a run in procedure for six weeks, during which blood pressure and heart rate were measured weekly as described below. All antihypertensive drugs were discontinued at the initial visit. The final criterion for entry was a mean diastolic blood pressure at the last three recordings of $90-104 \mathrm{~mm} \mathrm{Hg}$; this was also regarded as the baseline blood pressure. Consent was obtained from the patients after they had been given oral and written information about the study. They were randomly allocated to a treatment group by their birth date: patients born on even dates were allocated to the diet group and those born on uneven days to the drug treatment group.

Blood pressure was monitored every month during 
the study. The patients in both groups met the doctor $(\mathrm{AB}$ or $\mathrm{BF})$ six weeks before and at randomisation and three, six, and 12 months thereafter. If diastolic blood pressure was $\geq 105 \mathrm{~mm} \mathrm{Hg}$ at two consecutive measurements or $\geq 110 \mathrm{~mm} \mathrm{Hg}$ at any time drug treatment was given and the patient was excluded from the study. The occurrence of events defined above as exclusion criteria also prevented further participation in the study.

\section{TREATMENT GOALS AND METHODS}

The dietary programme aimed at reducing body weight at least $5 \%$, restricting sodium intake to $\leq 95 \mathrm{mmol} /$ day, decreasing alcohol intake in patients consuming $\geq 250 \mathrm{~g} /$ week, increasing the ratio of polyunsaturated to saturated fat in the diet to $\geq 0 \cdot 5$, and increasing potassium intake to at least $100 \mathrm{mmol} /$ day.

Every patient had an individual treatment goal that was decided in cooperation with the doctor. After dietary intake had been assessed the patients met the dietitian during the first month and after three, six, and 12 months. Three group meetings lasting for three hours were held during the first two months; five to 10 patients participated with their spouses, the dietitian, and one doctor.

Nutritional counselling was based on conventional principles aiming at a weight loss of $0.5 \mathrm{~kg} /$ week until a stable weight was reached. Fat intake was recommended to be below $30 \%$ of energy requirements with a parallel increase in complex carbohydrates to $50 \%$ and protein for the remainder. Meal patterns, basic nutrition, menu planning, and food selection and preparation were discussed, and the medical rationale for treatment was explained. The patients were taught to monitor their salt intake by recording the chloride concentration in urine on a dipslide test (Saltex, Miles Laboratories, Elkhait, Indiana). Every patient recorded body weight at home once a week. Determinations of body mass, urinary concentrations of sodium and potassium, and blood pressure were used as feedback to motivate the patients. Adherence to diet was also checked with diet records. Individual counselling on alcohol intake took place when participants met their doctor in the hypertension outpatient unit.

The pharmacological regimen was atenolol 50-100 mg once daily as first line treatment and bendrofluazide $2.5 \mathrm{mg}$ daily and nifedipine $10-20 \mathrm{mg}$ twice daily. Other agents and combinations were also allowed in case of adverse side effects or insufficient control of blood pressure.

\section{MEASUREMENTS}

Blood pressure was measured by specially trained nurses using a Hawksley random zero mercury sphygmomanometer with a cuff of appropriate size. Systolic blood pressure was recorded as appearance of the first sound and diastolic as disappearance of the last sound. The patients rested in the recumbent position for five minutes and the mean of two recordings was used. Heart rate was then measured by palpation of the radial pulse. The measurements were always made in the morning. In the drug treatment group the drugs were taken as usual on examination days - that is, in the early morning. After completing the study the patients were followed every second month and blood pressure was routinely measured. ${ }^{8}$

Body weight was recorded on a level balance scale to the nearest $0 \cdot 1 \mathrm{~kg}$ with the patient wearing trousers but not shoes, and body mass index calculated as weight $(\mathrm{kg}) /(\text { height }(\mathrm{m}))^{2}$.

Four day diet records with additional diet histories were assessed at baseline, six, and 12 months in the diet group. Those in the drug treatment group were not asked to record their eating habits until the end of the study so that changes would not be induced in their diet. The records were coded for computer analysis based on the Swedish food composition tables. ${ }^{9}$ Alcohol intake was estimated at baseline, six, and 12 months with a questionnaire covering the previous four weeks. ${ }^{10}$

Two 24 hour urine specimens were obtained from each patient during run in and at three, six, and 12 months. Sodium and potassium concentrations were determined by flame photometry and creatinine concentrations by the picrate method. During the run in period and after 12 months venous blood was drawn after an overnight fast to determine serum concentrations of total cholesterol, high density lipoprotein cholesterol, and triglycerides. "Low density cholesterol concentration was calculated with Friedewald's formula. ${ }^{12}$

In connection with the initial clinical examination a routine laboratory investigation determined baselines for erythrocyte sedimentation rate, blood haemoglobin concentration, and serum concentrations of sodium, potassium, calcium, and creatinine. Liver tests were carried out and urinary concentrations of glucose and protein determined by dipslide tests. ${ }^{8}$ A chest $x$ ray and a 12 lead electrocardiogram were obtained in each patient. The electrocardiogram was evaluated according to the Minnesota code. ${ }^{14}$ Results of noninvasive heart examinations and plethysmography of the forearm obtained at baseline and at the end of the study will be reported separately.

The study was approved by the ethical committee of the faculty of medicine, Gothenburg University.

\section{STATISTICAL METHODS}

In planning the study we considered a difference in diastolic blood pressure of $5 \mathrm{~mm} \mathrm{Hg}$ between the groups to be clinically important and assumed a standard deviation of $6 \mathrm{~mm} \mathrm{Hg}$. Allowing for probabilities of $5 \%$ for a type $1(\alpha)$ error and $10 \%$ for a type $2(\beta)$ error the calculated sample size was 30 subjects per group. The primary response variables for effect of the intervention were comparison of the percentage of patients achieving normal blood pressure (defined as diastolic blood pressure below $90 \mathrm{~mm} \mathrm{Hg}$ ) and changes in absolute blood pressure and serum lipid concentrations.

Results are expressed as means and standard deviations, and $95 \%$ confidence intervals are given for the main findings. The statistical analysis is based mainly on comparing changes in measured variables between the two groups. For body weight the initial values were calculated as the means of the two last measurements during the run in period and the final values as the means of body weights recorded in the 10th to 12th months. Similarly systolic and diastolic blood pressures and heart rates were calculated as means of the last three measurements in the run in and treatment periods. For urinary excretions of creatinine, sodium, and potassium the differences were calculated from the means of measurements at three to 12 months compared with basal values. Alcohol consumption during the treatment period is given as means of reported intakes after six and 12 months.

Distributions were compared with the MannWhitney $U$ test and Wilcoxon signed rank test. The effects of previous antihypertensive treatment and occurrence of left ventricular hypertrophy were analysed with $t$ tests. Categorical variables were compared using $\chi^{2}$ tests. The relation between success in attaining dietary goals and change in blood pressure was determined with Spearman's rank correlation coefficient $\left(r_{s}\right)$. A p value of $<0.05$ on two sided tests was regarded as significant. 


\section{Results}

Three patients in the diet group were excluded (one rejected further participation, and malignant disease was diagnosed in two). Characteristics of the remaining patients at entry are shown in table I. Higher proportions of patients with left ventricular hypertrophy and previous antihypertensive treatment were found in the diet group $(32 \% v 13 \%(\mathrm{p}<0.01)$ and $71 \%$ v $53 \%$ $(\mathrm{p}<0.05)$ respectively).

Twenty four patients were treated with a single drug during the trial (19 with atenolol, one with pindolol, two with bendrofluazide, one with nifedipine, and one with enalapril). Five patients received different combinations of atenolol and other agents (three with bendrofluazide, one with nifedipine, and one with hydralazin). One patient used bendrofluazide and nifedipine.

\section{DIETARY INTERVENTION}

Table II shows the results of analyses of the four day

TABLE I-Characteristics of patients at entry. Values are means (SD) unless otherwise indicated

\begin{tabular}{|c|c|c|}
\hline & $\begin{array}{l}\text { Diet treatment } \\
\quad(\mathbf{n}=31)\end{array}$ & $\begin{array}{l}\text { Drug treatment } \\
\quad(\mathrm{n}=30)\end{array}$ \\
\hline Age (years) & $54 \cdot 5(7 \cdot 8)$ & $53 \cdot 5(9 \cdot 7)$ \\
\hline Height $(\mathrm{m})$ & $1.78(0.04)$ & $1.79(0.06)$ \\
\hline Body weight $(\mathrm{kg})$ & $96 \cdot 9(10 \cdot 6)$ & $101 \cdot 9(11 \cdot 7)$ \\
\hline \multirow{2}{*}{\multicolumn{2}{|c|}{$\begin{array}{l}\text { Body mass index }\left(\mathrm{kg} / \mathrm{m}^{*}\right) \\
\% \text { With antihypertensive treatment }\end{array}$}} & $31 \cdot 6(3 \cdot 9)$ \\
\hline & & $53(\mathbf{n}=16)^{\star}$ \\
\hline$\%$ With left ventricular hypertrophy $\dagger$ & $32(\mathrm{n}=10)$ & $13(n=4) \star \star$ \\
\hline \multicolumn{3}{|l|}{ Blood pressure $(\mathrm{mm} \mathrm{Hg})$ : } \\
\hline Systolic & $152(15)$ & $155(13)$ \\
\hline Diastolic & $96(4)$ & $97(5)$ \\
\hline Heart rate (beats $/ \mathrm{min})$ & $72(11)$ & $69(9)$ \\
\hline \multicolumn{3}{|l|}{ Serum cholesterol $(\mathrm{mmol} / \mathrm{l})$ : } \\
\hline Total & $5.92(1.01)$ & $5 \cdot 63(1 \cdot 19)$ \\
\hline High density lipoprotein & $1 \cdot 15(0 \cdot 21)$ & $1 \cdot 32(0 \cdot 36)$ \\
\hline Low density lipoprotein $\ddagger$ & $3.99(0.97)$ & $3 \cdot 70(1 \cdot 14)$ \\
\hline Total/high density lipoprotein & $5 \cdot 37(1 \cdot 51)$ & $4 \cdot 50(1 \cdot 2)$ \\
\hline Serum triglycerides $(\mathrm{mmol} / \mathrm{l})$ & $1.74(0 \cdot 78)$ & $1.38(0.55)$ \\
\hline \multicolumn{3}{|l|}{ Urinary concentrations $(\mathrm{mmol} / 24 \mathrm{~h})$ of: } \\
\hline Creatinine & $15 \cdot 9(3 \cdot 1)$ & $15 \cdot 9(3 \cdot 1)$ \\
\hline Sodium & $169(39)$ & $183(65)$ \\
\hline Potassium & $82(17)$ & $79(28)$ \\
\hline
\end{tabular}

TABLE II - Dietary intake according to four day diet records. Values are means (SD)

\begin{tabular}{|c|c|c|c|c|}
\hline & \multicolumn{2}{|c|}{$\begin{array}{l}\text { Diet treatment } \\
\qquad(\mathrm{n}=28)\end{array}$} & \multirow{2}{*}{$\begin{array}{l}\text { Drug treatment } \\
(\mathrm{n}=26) \\
12 \text { months }\end{array}$} & \multirow{2}{*}{$\begin{array}{c}\mathrm{p} \mathrm{Value} \\
\text { for difference } \\
\text { in means at } \\
12 \text { months }\end{array}$} \\
\hline & 0 months & 12 months & & \\
\hline $\begin{array}{l}\text { Energy (kJ/day) } \\
\text { (kcal/day) }\end{array}$ & $\begin{array}{l}10400(2100) \\
2500(500)\end{array}$ & $\begin{array}{l}8600(1800) \\
2000(400)\end{array}$ & $\begin{array}{l}10000(2300) \\
(2400(500))\end{array}$ & $0 \cdot 03$ \\
\hline $\begin{array}{l}\text { Protein }(\% \text { of energy intake }) \\
\text { Carbohvdrates }(\% \text { of }\end{array}$ & $15(3)$ & $17(2)$ & $16(7)$ & $0 \cdot 46$ \\
\hline energy intake) & $43(7)$ & $48(8)$ & $44(6)$ & 0.027 \\
\hline $\begin{array}{l}\text { Fat ( } \% \text { of engery intake) } \\
\text { Ratio of polvunsaturated }\end{array}$ & $38(6)$ & $30(5)$ & $37(8)$ & $0 \cdot 0001$ \\
\hline $\begin{array}{l}\text { to saturated fat } \\
\text { Alcohol (\% of energy intake) }\end{array}$ & $\begin{array}{l}0 \cdot 36(0 \cdot 12) \\
4(6)\end{array}$ & $\begin{array}{l}0 \cdot 53(0 \cdot 25) \\
5(7)\end{array}$ & $\begin{array}{l}0 \cdot 34(0 \cdot 13) \\
3(3)\end{array}$ & $\begin{array}{l}0 \cdot 0008 \\
0 \cdot 43\end{array}$ \\
\hline
\end{tabular}

diet records obtained at baseline in the diet group and after 12 months in both groups. The dietary programme reduced energy intake $(1800(\mathrm{SD} 1900) \mathrm{kJ}, \mathrm{p}<0 \cdot 0001)$ by decreasing the amount of fat and protein consumed by $8(6) \%$ of energy intake $(p<0 \cdot 0001)$ and $3(3) \%$ of energy intake $(\mathrm{p}<0.0001)$ respectively while increasing the intake of carbohydrates by $5(7) \%$ of energy intake $(p=0.0014)$. The average ratio of polyunsaturated to saturated fat in the diet showed a significant increase $(0.18(0 \cdot 26), \mathrm{p}=0.0014)$ to above the stated goal of 0.5 . Of the patients in the diet group 32\% (9/28) reached this goal compared with $12 \%(3 / 26)$ in the drug treatment group.

Table III shows body weights and urinary excretions of creatinine, sodium, and potassium. Body weight decreased by $7.6(3.1) \mathrm{kg}$ in the diet group and increased by $0.9(2.3) \mathrm{kg}$ in the drug treatment group $(\mathrm{p}<0.0001)$. A weight loss of $5 \%$ or more was attained by 26 of the 31 patients in the diet group and none of the patients in the drug treatment group. Creatinine excretion did not show any significant changes within or between groups. Excretion of sodium was reduced by $42(48) \mathrm{mmol} / 24 \mathrm{~h}$ in the diet group and $10(54)$ $\mathrm{mmol} / 24 \mathrm{~h}$ in the drug treatment group $(\mathrm{p}<0.02)$. A mean sodium output $\leq 95 \mathrm{mmol} / 24 \mathrm{~h}$ was found in $23 \%$ (7/31) of the diet group and 3\% (1/30) of the drug group during treatment. Potassium excretion did not differ between the groups, and $10 \%(3 / 31)$ of the patients treated with diet and $13 \%(4 / 30)$ given drug treatment had outputs $\geq 100 \mathrm{mmol} / 24 \mathrm{~h}$.

Analyses of the questionnaires on alcohol consumption showed that the intake at baseline was $67(88) \mathrm{g} /$ week of pure ethanol in the diet group and $70(89)$ $\mathrm{g} /$ week in the drug treatment group. The corresponding values during treatment were 72 (95) and 71 (93) $\mathrm{g} /$ week. The change between the groups was not significant. The proportions of patients consuming 250 $\mathrm{g}$ or more of alcohol a week during the study were $10 \%$ $(3 / 31)$ in the diet group and $7 \%(2 / 30)$ in the drug treatment group.

\section{BLOOD PRESSURE AND HEART RATE}

Table IV shows blood pressure and heart rate during treatment. Systolic blood pressure decreased by 4 (11) $\mathrm{mm} \mathrm{Hg}$ in the diet group and by $16(12) \mathrm{mm} \mathrm{Hg}$ in the drug group $(p=0 \cdot 0003)$. The corresponding values for diastolic blood pressures were reductions of $3(6)$ and $11(6) \mathrm{mm} \mathrm{Hg},(\mathrm{p}=0.0001)$. Heart rate decreased by 3 (8) beats/min in the diet group and $9(8)$ beats $/ \mathrm{min}$ in the drug treatment group $(\mathrm{p}=0.0022)$.

A diastolic blood pressure $<90 \mathrm{~mm} \mathrm{Hg}$ was attained by $29 \%(9 / 31)$ of patients in the diet group and $73 \%(22 /$ $30)$ of those given drug treatment $(95 \%$ confidence intervals $14 \%$ to $48 \%$ and $54 \%$ to $88 \%$, respectively), a difference of $44 \%(21 \%$ to $67 \%, p<0.001)$. The final diastolic blood pressures and reductions in diastolic blood pressures during the trial are shown in table $\mathrm{V}$.

TABLE III - Body weights and daily urinary excretion of creatinine, sodium, and potassium in diet treatment $(n=31)$ and drug treatment $(n=30)$ groups before and during one year of treatment. Values are means $(S D)$; blanks indicate test not done

\begin{tabular}{|c|c|c|c|c|c|c|c|c|}
\hline \multirow{2}{*}{$\begin{array}{c}\text { Time } \\
\text { (months) }\end{array}$} & \multicolumn{2}{|c|}{$\begin{array}{l}\text { Body weight } \\
\quad(\mathrm{kg})\end{array}$} & \multicolumn{2}{|c|}{$\begin{array}{l}\text { Creatinine } \\
(\mathrm{mmol} / 24 \mathrm{~h})\end{array}$} & \multicolumn{2}{|c|}{$\begin{array}{l}\text { Sodium } \\
(\mathrm{mmol} / 24 \mathrm{~h})\end{array}$} & \multicolumn{2}{|c|}{$\begin{array}{l}\text { Potassium } \\
(\mathrm{mmol} / 24 \mathrm{~h})\end{array}$} \\
\hline & Diet & Drug & Diet & Drug & Diet & Drug & Diet & Drug \\
\hline Run-in & $96 \cdot 9(10 \cdot 6)$ & $101 \cdot 9(11 \cdot 7)$ & $15 \cdot 9(3 \cdot 1)$ & $15 \cdot 9(3 \cdot 1)$ & $169(39)$ & $183(65)$ & $82(17)$ & $79(28)$ \\
\hline $\begin{array}{l}1 \\
2\end{array}$ & $\begin{array}{l}94 \cdot 3(11 \cdot 2) \\
93 \cdot 0(11 \cdot 5)\end{array}$ & $\begin{array}{l}102 \cdot 6(12 \cdot 4) \\
102 \cdot 1(11 \cdot 9)\end{array}$ & & & & & & \\
\hline 3 & $90 \cdot 0(10 \cdot 1)$ & $102 \cdot 8(12 \cdot 2)$ & $15 \cdot 8(2 \cdot 6)$ & $15 \cdot 2(2 \cdot 6)$ & $131(50)$ & $173(47)$ & $81(18)$ & $79(24)$ \\
\hline 4 & $90 \cdot 3(11 \cdot 4)$ & $102.6(11.8)$ & & & & & & \\
\hline 5 & $89.8(11.5)$ & $103 \cdot 4(11 \cdot 8)$ & & & & & & \\
\hline 6 & $89 \cdot 3(11 \cdot 4)$ & $102 \cdot 8(11 \cdot 1)$ & $14 \cdot 3(2 \cdot 8)$ & $14 \cdot 7(2 \cdot 7)$ & $121(49)$ & $169(70)$ & $74(24)$ & $77(27)$ \\
\hline 7 & $89 \cdot 1(11 \cdot 0)$ & $102.8(11.4)$ & & & & & & \\
\hline 8 & $89.1(11.0)$ & $103 \cdot 6(11 \cdot 1)$ & & & & & & \\
\hline 9 & $88 \cdot 2 \quad(9 \cdot 7)$ & $104 \cdot 7(10 \cdot 7)$ & & & & & & \\
\hline 10 & $89.4(11.0)$ & $103 \cdot 5(11 \cdot 3)$ & & & & & & \\
\hline 11 & $88.3 \quad(9.9)$ & $105 \cdot 0(11 \cdot 1)$ & & & & & & \\
\hline 12 & $89 \cdot 1(11 \cdot 2)$ & $102.9(11.6)$ & $14 \cdot 8(2 \cdot 9)$ & $14 \cdot 3(4 \cdot 1)$ & $127(49)$ & $169(70)$ & $81(23)$ & $67(27)$ \\
\hline
\end{tabular}


TABLE IV-Blood pressure and heart rate in diet treatment $(n=31)$ and drug treatment $(n=30)$ groups before and during one year of treatment. Values are means $(S D)$

\begin{tabular}{|c|c|c|c|c|c|c|}
\hline \multirow{2}{*}{$\begin{array}{c}\text { Time } \\
\text { (months) }\end{array}$} & \multicolumn{2}{|c|}{$\begin{array}{c}\text { Systolic blood } \\
\text { pressure } \\
(\mathrm{mm} \mathrm{Hg}) \\
\end{array}$} & \multicolumn{2}{|c|}{$\begin{array}{c}\text { Diastolic } \\
\text { pressure } \\
(\mathrm{mm} \mathrm{Hg})\end{array}$} & \multicolumn{2}{|c|}{$\begin{array}{l}\text { Heart rate } \\
\text { (beats/min) }\end{array}$} \\
\hline & Diet & Drug & Diet & Drug & Diet & Drug \\
\hline Run in & $152(15)$ & $155(13)$ & $96(4)$ & $97(5)$ & $72(11)$ & $69(9)$ \\
\hline 1 & $149(15)$ & $139(14)$ & $94(7)$ & $87(8)$ & $69(12)$ & $61(8)$ \\
\hline 2 & $146(15)$ & $139(15)$ & $92(8)$ & $86(7)$ & $68(10)$ & $59(10)$ \\
\hline 3 & $146(16)$ & $143(14)$ & $93(7)$ & $88(7)$ & $68(9)$ & $61(7)$ \\
\hline 4 & $145(18)$ & $139(14)$ & $92(8)$ & $87(7)$ & $70(10)$ & $62(11)$ \\
\hline 5 & $145(17)$ & $143(16)$ & $91(7)$ & $89(7)$ & $68(11)$ & $62(9)$ \\
\hline 6 & $148(18)$ & $141(15)$ & $93(7)$ & $87(7)$ & $66(11)$ & $59(6)$ \\
\hline 7 & $149(18)$ & $141(16)$ & $92(8)$ & $87(7)$ & $67(10)$ & $62(8)$ \\
\hline 8 & $147(16)$ & $139(15)$ & $91(5)$ & $86(7)$ & $68(10)$ & $60(8)$ \\
\hline 9 & $146(18)$ & $139(15)$ & $92(7)$ & $89(8)$ & $67(11)$ & $61(8)$ \\
\hline 10 & $148(16)$ & $139(14)$ & $94(6)$ & $85(6)$ & $71(11)$ & $60(7)$ \\
\hline 11 & $146(15)$ & $140(16)$ & $92(6)$ & $86(7)$ & $67(8)$ & $60(8)$ \\
\hline 12 & $147(15)$ & $140(16)$ & $92(7)$ & $86(8)$ & $67(8)$ & $60(8)$ \\
\hline $\begin{array}{c}\text { Mean during } \\
\text { treatment }\end{array}$ & $147(14)$ & $141(12)$ & $92(5)$ & $87(5)$ & $68(8)$ & $61(7)$ \\
\hline
\end{tabular}

TABLE $\mathrm{v}-$ Diastolic blood pressure after one year of treatment and change in diastolic blood pressure during treatment

\begin{tabular}{ccc}
\hline $\begin{array}{c}\text { Diastolic blood } \\
\text { pressure }(\mathrm{mm} \mathrm{Hg})\end{array}$ & $\begin{array}{c}\text { Diet treatment } \\
(\mathrm{n}=31)\end{array}$ & $\begin{array}{c}\text { Drug treatment } \\
(\mathrm{n}=30)\end{array}$ \\
\hline & After one vear of treatment & \\
$75-79$ & 2 & 4 \\
$80-84$ & 7 & 7 \\
$85-89$ & 13 & 11 \\
$90-94$ & 6 & 5 \\
$95-99$ & 3 & 3 \\
$100-104$ & Change during treatment & \\
& & 1 \\
-30 to -26 & 1 & 1 \\
-25 to -21 & 1 & 8 \\
-20 to -16 & 9 & 7 \\
-15 to -11 & 12 & 2 \\
-10 to -6 & 4 & 2 \\
-5 to -1 & 4 & \\
0 to 4 & & \\
5 to 9 & &
\end{tabular}

TABLE VI-Changes in serum lipid concentrations from baseline to end of one year of treatment. Values are means $(S D)$

\begin{tabular}{|c|c|c|c|}
\hline & $\begin{array}{l}\text { Diet treatment } \\
\quad(\mathrm{n}=28)\end{array}$ & $\begin{array}{l}\text { Drug treatment } \\
\quad(\mathrm{n}=29)\end{array}$ & $\begin{array}{l}\mathrm{p} \text { Value of } \\
\text { difference }\end{array}$ \\
\hline Total cholesterol $(\mathrm{mmol} / \mathrm{l})$ & $-0.33(0.85)$ & $0.04(0.55)$ & 0.082 \\
\hline $\begin{array}{l}\text { High density lipoprotein } \\
\text { cholesterol }(\mathrm{mmol} / \mathrm{l})\end{array}$ & $0.09(0.17)$ & $-0 \cdot 13(0 \cdot 33)$ & $<0.001$ \\
\hline $\begin{array}{l}\text { Low density } \\
\text { lipoprotein cholesterol } \\
(\mathrm{mmol} / \mathrm{l})\end{array}$ & $-0 \cdot 32(0 \cdot 68)$ & $-0.02(0 \cdot 62)$ & 0.037 \\
\hline $\begin{array}{l}\text { Ratio of total to high density } \\
\text { lipoprotein cholesterol } \\
\text { Triglycerides }(\mathrm{mmol} / \mathrm{l})\end{array}$ & $\begin{array}{l}-0.80(1 \cdot 16) \\
-0.23(0.89)\end{array}$ & $\begin{array}{l}0.45(0.87) \\
0.42(0.72)\end{array}$ & 0.0001 \\
\hline
\end{tabular}

\section{SERUM LIPID CONCENTRATIONS}

Table VI shows changes in serum lipid concentrations. Diet treatment was associated with decreases in concentrations of low density lipoprotein cholesterol and triglycerides and an increase in concentration of high density lipoprotein cholesterol, leading to a reduction in the ratio of total to high density lipoprotein cholesterol. Drug treatment caused changes in the opposite directions, and the differences between groups were significant.

\section{WITHIN GROUP ANALYSIS}

Twenty two patients in the diet group and 16 in the drug treatment group had received antihypertensive treatment before the study. During the trial they reduced their diastolic blood pressure by 2 (6) and 10 (7) $\mathrm{mm} \mathrm{Hg}$ respectively, the exact difference being $-8.8 \mathrm{~mm} \mathrm{Hg}$. The patients who had not taken drugs (nine in the group treated with diet and 14 in the group given drug treatment) had reductions in diastolic blood pressure of 6 (4) and $12(6) \mathrm{mm} \mathrm{Hg}$, respectively, a difference of $-6 \mathrm{~mm} \mathrm{Hg}$. The difference between the differences was -3 (6) $\mathrm{mm} \mathrm{Hg}$, which was not significant ( $95 \%$ confidence interval -9 to $3 \mathrm{~mm} \mathrm{Hg}$ ). Within the diet group, however, previous antihypertensive treatment was associated with a significantly lower decrease in diastolic blood pressure than was no previous treatment $(\mathrm{p}=0.03)$.

Electrocardiograms of 10 patients in the diet group and four in the drug group showed left ventricular hypertrophy. In these patients mean diastolic blood pressure decreased by 2 (8) and 15 (8) $\mathrm{mm} \mathrm{Hg}$ respectively and in the remaining patients by $4(5)$, and it decreased by $4(5) \mathrm{mm} \mathrm{Hg}$ in the diet group and 11 (6) $\mathrm{mm} \mathrm{Hg}$ in the drug treatment group. When the differences were compared the final difference was -6 (6) $\mathrm{mm} \mathrm{Hg}$, which was not significant $(95 \%$ confidence interval -14 to $2 \mathrm{~mm} \mathrm{Hg}$ ).

In the diet group the change in diastolic blood pressure during the study was not significantly correlated to baseline body mass index $\left(r_{s}=0.06\right)$, weight loss during treatment $\left(r_{s}=0 \cdot 28\right)$, change in sodium output $\left(r_{\mathrm{s}}=0.31\right)$, or change in alcohol intake $\left(r_{\mathrm{s}}=\right.$ $0 \cdot 14)$.

\section{FOLLOW UP}

The patients in the diet group were followed up every second month for a mean of 14 (range 4-21) months after treatment $(n=31)$. Mean body weight increased by $2.6(3.0) \mathrm{kg}(\mathrm{p}<0.001)$. Five $(16 \%)$ had a diastolic blood pressure below $90 \mathrm{~mm} \mathrm{Hg}$ and were taking no antihypertensive drugs.

\section{Discussion}

The first aim of this study was to design a dietary programme and evaluate its effectiveness and feasibility. The cornerstone of the programme was weight reduction, which is generally considered to be the most effective change in lifestyle. ${ }^{214}$ Our definition of obesity compared well with that of other investigators ${ }^{15-18}$ as well as with the recommendations of a consensus development conference. ${ }^{6} \mathrm{~A}$ goal of at least $5 \%$ reduction in body weight was expected to cause a mean decrease in diastolic blood pressure of 6-7 $\mathrm{mm}$ $\mathrm{Hg}{ }^{1920}$ and is in line with the intervention goal in another well known study. ${ }^{16}$ To our knowledge there have been two controlled studies of untreated patients lasting for a year or more that used diet in treating hypertension, both from the United States: the dietary intervention study in hypertension and the hypertension control programme..$^{15}$ The average weight loss in these patients was 4.0 and $1.8 \mathrm{~kg}$ respectively, compared with $7.6 \mathrm{~kg}$ in our study. Moreover, a reduction in body weight of $5 \%$ or more was attained by $84 \%$ of patients in our study compared with $46 \%$ and $30 \%$ in the two other reports. On the basis of our previous experience ${ }^{10}$ we defined an intervention goal for sodium intake of $<95 \mathrm{mmol} / 24 \mathrm{~h}$; this was higher than in the other two studies $(70$ and $74 \mathrm{mmol} / 24 \mathrm{~h}$, respectively). ${ }^{15} 16$ Our measurements of urinary creatinine excretion indicated that the patients had collected urine as instructed; the mean daily output of sodium decreased by $42 \mathrm{mmol} / 24 \mathrm{~h}$ in this trial compared with $44-59$ and $60 \mathrm{mmol} / 24 \mathrm{~h} .^{15} 16$

The association between excessive alcohol consumption and hypertension is well documented, and a reduced intake is strongly advocated. ${ }^{124}$ We used roughly the same treatment goals as did the hypertension control programme. Taking into account the uncertain validity of self reporting we found a low proportion of high consumers of alcohol; we did not succeed in changing their consumption. Neither did the American study report significant changes in this respect. ${ }^{16}$

Though there is no consistent evidence of their antihypertensive effects, ${ }^{2+}$ we also included increases in dietary potassium and the ratio of polyunsaturated 
to saturated fat in the programme. These measures are, however, in line with general food recommendations that aim at increasing the consumption of fruit, vegetables, and polyunsaturated fat and decreasing the intake of saturated fat; this is known to lower serum cholesterol concentrations. ${ }^{21}$ The potassium intake, as measured from daily urinary excretion, did not increase. The mean ratio of polyunsaturated to saturated fat increased above 0.5 and was attained by a third of the patients. This estimation was, however, based on periodic diaries, which may not adequately reflect long term patterns. Even so, there was an acceptable concordance between the reduction in reported total intake of energy and observed mean weight loss. According to their diet records the patients had also followed the recommendations on intake of nutritients, decreasing their intake of fats and increasing their intake of carbohydrates. Thus, we found that the recommended diet was at least as feasible and effective in achieving dietary goals as were similar programmes in earlier studies. ${ }^{15} 16$

The main purpose of the study was to evaluate the effects of this non-pharmacological approach on blood pressure in comparison with conventional antihypertensive treatment. All such trials have inevitably been unblinded. ${ }^{15-20}$.We tried to improve the experimental conditions by using blinded blood pressure readings taken by specially trained nurses, who took no active part in treating the patients. Any potential observer bias should have favoured the non-pharmacological regimen and reinforced the finding that diet was less effective both in terms of number of patients becoming normotensive as well as in terms of absolute fall in blood pressure.

The higher proportion of patients with more severe forms of hypertension in the diet group may have weakened the effect of treatment in that group. The groups were not dissimilar in terms of average blood pressure at baseline, but more patients in the diet group had evidence of left ventricular hypertrophy. The statistical analysis, however, showed that this difference between the groups had no great influence on diastolic blood pressure at the end of the study. The diet group also contained more patients previously treated for hypertension ( $22 v 16)$, which was associated with a poorer response to intervention than in those not treated previously. The observation is in line with studies showing that hypertension recurs in most patients within one year of stopping drugs. ${ }^{22}$ Further analysis, however, did not show any difference between the groups in the influence of previous antihypertensive treatment. The hypertension control programme which examined only hypertensive patients after drug withdrawal and with the same end points as we used, had a success rate of $69 \%$ after one and $39 \%$ after four years, ${ }^{16}$ compared with $29 \%$ after one and $16 \%$ after two years in our patients. Even when the $95 \%$ confidence interval of $14 \%$ to $48 \%$ for our value at one year is considered there is a clear difference in results, despite our greater success in obtaining weight reduction.

In this context it may be pertinent to compare our results with the often cited studies by Reisin $e t a l^{77}$ and MacMahon $e t$ al ${ }^{18}$. Reisin $e t$ al showed that an average weight loss of $8 \cdot 8 \mathrm{~kg}$ during four months was associated with a mean decrease in blood pressure of $26 / 20 \mathrm{~mm}$ Hg. ${ }^{17}$ MacMahon et al reported that blood pressure decreased a mean of $13 / 10 \mathrm{~mm} \mathrm{Hg}$ at the end of five months of a diet regimen that led to a weight loss of $7 \cdot 4$ $\mathrm{kg}$, which was superior to placebo and to metoprolol $200 \mathrm{mg}$ daily. ${ }^{18}$ In contrast, we obtained a mean reduction of $7.6 \mathrm{~kg}$ in body weight and of $4 / 3 \mathrm{~mm} \mathrm{Hg}$ in blood pressure. These differences may be explained by differences in patient selection, proportion of participants previously treated, run in procedure, type of diet, establishing a new steady state, and, above all, duration of the study. Our patients were not more obese, however, nor were our intervention goals for weight reduction too conservative in comparison with these studies. Finally, one randomised, controlled study showed no antihypertensive effect of weight reduction, ${ }^{23}$ lending support to our findings that weight reduction may not effectively lower blood pressure. In addition, our follow up more than two years after treatment indicated a further, important decrease in the number of patients remaining normotensive with non-pharmacological treatment.

The study was designed to test the impact of a comprehensive diet programme and not the effect of single factors. The basis for analysis was comparisons between groups, but within group analysis was carried out to examine whether varying individual responses in blood pressure to the diet could be related to specific characteristics of the patients or to their compliance. This variability could not be explained by the initial degree of obesity or different degrees of reduction in body weight, sodium intake, or alcohol consumption.

Treatment with diet resulted in an overall beneficial effect on concentrations of low density lipoprotein and high density lipoprotein cholesterol, the ratio of total cholesterol to high density lipoprotein cholesterol, and concentrations of triglycerides. Treatment with antihypertensive drugs, mainly selective $\beta_{1}$ blockade, was associated with unfavourable changes in the opposite direction. All these findings accord with those of previous reports. ${ }^{161724}$

The present study comparing the effects of a multifactorial nutritional programme and conventional antihypertensive drug treatment on obese hypertensive men is a small study, and its results are not generally applicable to the hypertensive population as the patients were not randomly selected; this is also indicated by the low drop out rate. The results may, however, be applied to treating well motivated patients. The experimental design was close to everyday clinical practice in that the aim of treatment was to obtain normal blood pressure according to generally accepted recommendations ${ }^{12}$ and with access to all common antihypertensive drugs. The study showed that diet treatment was not as effective as drug treatment in lowering blood pressure, but diet treatment had beneficial effects on serum lipid concentrations, whereas antihypertensive drugs showed adverse effects. The true prognostic importance of combined changes in blood pressure and serum lipids remains to be determined.

This study was supported by grants from the Swedish Council for Planning and Coordination of Research and the Swedish Heart Lung Foundation. Dr Nils Blomqvist helped with study design and outlining the analytical work. Excellen help was provided by our dietitians Christine Jörnbratt and Maude Enervo. Christina Lundin, Gunilla Vilén, Eva-Lena Alenhag, technical assistants, also provided invaluable help.

1 Amery A, Anlauf M, Beilin LJ, et al. 1986 Guidelines for the treatment of mild by A, Anlau M, Beilin LJ, et al. 1986 Guidelines hypertension.
8:957-61.

2 Subcommittee on Nonpharmacological Therapy of the 1984 Joint Nationa Committee on Detection, Evaluation, and Treatment of High Blood Pressure. Nonpharmacological approaches to the control of high blood pressure. Hypertension 1986;8:444-67

3 Anonymous. Weight reduction in hypertension [Editorial]. Lancet 1985; $1251-2$

+ Beilin LJ. State of the art lecture. Diet and hypertension: critical concepts and controversies. F Hypertens 1987;5(suppl 5):447-57.

Puska P, Iacono JM, Nissinen A, et al. Controlled randomized trial of the effect of dietary fat on blood pressure. Lancet $1983 ; \mathrm{i}: 1-5$.

Burton BT, Foster WR, Hirsch J Van Itallie TB. Health implications of obesity: an N1H consensus development conference. Int f Obesity 1985; 9.155-69.

7 WHO Study Group. Diabetes mellitus. Geneva: World Health Organisation, 1978. Technical report series 727 .

8 Andersson $\mathrm{O}$, Berglund $\mathrm{G}$, Hansson $\mathrm{L}$, et al. Organization and efficacy of an out-patient hypertension clinic. Acta Med Scand 1978;203:391-8.

9 Statens Livsmedelsverk. Food composition tables. Stockholm: Liber Tryck, 1978

10 Fagerberg B, Andersson OK, Isaksson B, Björntorp P. Blood pressure contro 
during weight reduction in obese hypertensive men: separate effects of sodium and energy restriction. Br.Med $\mathcal{F} 1984 ; 288: 11-4$

11 Wiklund O, Fager G, Craigh IH, et al. Alphalipoprotein cholesterol in relation to acute myocardial infarction and its risk factors. Scand $\mathcal{J}$ Clin Lab Invest 1980;40:239-48

12 Friedewald WT, Levy RL, Fredrickson DS. Estimation of the concentration of low density lipoprotein cholesterol in plasma without use of the preparative ultracentrifuge. Clin Chem 1972;18:499-502.

13 Rose GA, Blackburn H. Cardiovascular survey methods. Geneva: World Health Organisation, 1968. (Monograph series No 6.)

+ Andrews G, MacMahon SW, Austin A, Burne D)(i. Hupertension: comparison of drug and non-drug treatments. Br Med J 1982:284:1523-6.

15 Langford HG, Blaufox MD, Oberman A, et al. Diet therapy slows the return of hypertension after stopping prolonged medication. FAMA 1985; 253:657. hypert

16 Stamler R, Stamler J, Grimm R, et al. Nutritional therapy for high blood pressure. Final report of a four-year randomized controlled trial-th hypertension control program. FAMA 1987;257:1484-91

17 Reisin E, Abel R, Modan M, Silverberg DS, Eliahou HE, Modan B. Effect of weight loss without salt restriction on the reduction of blood pressure in overweight hypertensive patients. N Engl f. Med 1978;298:1-6.
18 Macilahon SW, MacDonald GJ, Bernstein L, Andrews G, Blacket RB. Comparison of weight reduction with metoprolol in treatment of hypertension in young overweight patients. Lancet 1985; ;:1233-6.

19 Ramsay LE, Ramsey MH, Hettiarachichi J, Davies DL, Winchester J. Weight reduction in blood pressure clinic. Br.Med f 1978;ii:244-5.

20 Eliahahou HE, Iaina A, Gaon T, Shochat J Modan M. Body weight reduction necessary to attain normotension in the overweight hypertensive patient. Int 7 Obesity 1981:5 (suppl 1):157-63.

21 Bruce $\mathrm{A}$. The new Swedish nutrition recommendations (English summary Var Födu 1981:33:354-72.

22 Ljungman S, Aurell MI, Hartford $M$, Wikstrand J, Berglund $\mathrm{G}$. Renal function and renal hemodsnamics before and after 7 years antihypertensive treatmen in men with primary hypertension Acta Med Scand [Suppl] 1984:693:89-92.

23 Haynes RB, Harper AC, Costley SR, et al. Failure of weight reduction to reduce mildly clevated blood pressure: a randomized trial. I Hyperen $1984 ; 2: 535-9$

24 Wolf RN, Grundy SM. Influence of weight reduction on plasma lipoproteins in obese patients. Arteriosclerosis 1983;3:160-9.

Accepled 31. Hay 1989:

\title{
Recovery after subarachnoid haemorrhage
}

\author{
P McKenna, J R Willison, D Lowe, G Neil-Dwyer
}

\begin{abstract}
Objective-To determine the implications of subarachnoid haemorrhage for quality of life and aftercare.

Design-Prospective follow up study of patients surviving subarachnoid haemorrhage over one year (at discharge, three months, and one year) by examination of cognitive functions (a test battery) and changes in everyday life (semistructured interview).
\end{abstract}

Setting-Regional neurosurgical unit at a tertiary referral centre.

Patients-100 Patients with subarachnoid haemorrhage; 17 were lost during the study because of ineligibility (further surgery, previous head injury, relevant psychiatric history, and cultural differences), loss of contact, and non-compliance; a further 13 patients who developed a neurological deficit were considered separately.

Main outcome measure-Performance on cognitive test battery and reported changes in quality of life.

Results-At discharge patients with and without neurological deficit scored below established norms with most tests, but by three months the difference had resolved in patients without deficit. Reduced quality of life attributable to subarachnoid haemorrhage at one year mainly included less energy (seven patients), adverse emotional changes (five), early retirement, affected social life, and domestic tension (three each). None reported reduced capacity for work.

Conclusions-Patients surviving subarachnoid haemorrhage without neurological symptoms have a good prognosis and should be encouraged to return to a normal lifestyle within about three months.

\section{Royal Free Hospital, London \\ J R Willison, PHD, clinical psychologist}

\section{King's College Medical}

School, London

D Lowe, MSc, research statistician, department of community medicine

Correspondence to: Miss $\mathrm{P}$ McKenna, Rookwood Hospital, Llandaff, Cardiff CF5 2YN. primary care often have little experience of patient who have had a haemorrhage. Many papers have been published on subarachnoid haemorrhage, but virtually none is of use to those who are concerned in aftercare. Moreover, it may take many years for a representative sample of patients to pass through a general practice. The need for better information became clear to us while conducting a follow up study of 100 patients recovering from a subarachnoid haemorrhage. We found that when patients were discharged back to the care of their general practitioners many of the doctors were unable to comment on the minor problems their patients described and often referred patients to the neurosurgeon - a lengthy route for a few words of reassurance, which was sometimes the only treatment required.

Trying to learn about subarachnoid haemorrhage from current publications would only confuse the nonspecialist. Though earlier studies tended to report excellent recovery rates,,$^{2}$ more recent researchers claim that the closer they looked the more they found in terms of impaired intellect and impoverished quality of life. ${ }^{+5}$ In these investigations, based on retrospective group studies, the patient was often assessed many years after the event: thus the results have a limited application in treating patients in the first few months of convalescence.

We describe the implications for the aftercare of patients who have had a subarachnoid haemorrhage in a one year prospective follow up study of a representative sample of patients at the South East Thames regional neurosurgical unit, Brook Hospital, London.

\section{Patients and methods}

One hundred patients with a diagnosis of subarachnoid haemorrhage constituted the experimental group. Each patient was assessed three times: at initial discharge from hospital, at three months, and at one year. The assessment consisted of a two hour examination of cognitive functions using a test battery derived from the psychology department of the National Hospital for Nervous Diseases, London. ${ }^{6}$ A semistructured interview with a close friend or relative of the patient (often a spouse) was carried out at each assessment, and questionnaires on mood and behaviour were also used. ${ }^{6}$ The most valuable source of information was found to be the semistructured interview, which could be tailored to suit the idiosyncrasies of each patient. The contribution of the illness to the overall quality of life (work and social and domestic life) was judged from these data.

\section{Results}

Of the 100 patients with subarachnoid haemorrhage who entered the study, 17 were lost during their first year through ineligibility (because of the need for further surgery, a previous head injury, relevant 